
\title{
25 Research Square \\ Cerebral Hemodyanamics in Stable Preterm Infants Before and After Packed Cell Transfusion
}

\section{Chinmay Chetan}

Bharati Vidyapeeth Deemed University

\section{Nyein Zaw}

Women and Children Hospital, Taunggyi

Pradeep Suryawanshi ( $\nabla$ drpradeepsuryawanshi@gmail.com )

Bharati Vidyapeeth Deemed University

\section{Nishant Banait}

Bharati Vidyapeeth Deemed University

\section{Prince Pareek}

Bharati Vidyapeeth Deemed University

\section{Sujata Deshpande}

Bharati Vidyapeeth Deemed University

\section{Bhvya Gupta}

Bharati Vidyapeeth Deemed University

\section{Reema Garegrat}

Bharati Vidyapeeth Deemed University

\section{Arjun Verma}

Bharati Vidyapeeth Deemed University

\section{Research Article}

Keywords: Packed cell volume transfusion, USG Doppler study, Peak systolic velocity, End diastolic velocity, Resistive index, Stable preterm infants.

Posted Date: December 11th, 2020

DOl: https://doi.org/10.21203/rs.3.rs-121066/v1

License: (c) (1) This work is licensed under a Creative Commons Attribution 4.0 International License. Read Full License

Version of Record: A version of this preprint was published at Journal of Nepal Paediatric Society on December 31st, 2021. See the published version at https://doi.org/10.3126/jnps.v41i3.36444. 


\section{Abstract}

BACKGROUND In a year around 3.5 million preterm deliveries occur in India alone. Some of these babies will require packed cell volume (PCV) transfusion. There is a paucity of robust data on effect of blood transfusions on the cerebral hemodynamic from India. This study was done to see the effect of PCV transfusion on blood flow velocities and resistive index (RI) of anterior cerebral artery (ACA) in stable preterm infants.

METHOD A prospective observational study was conducted in a tertiary care hospital in Pune, India. All stable preterm infants (<37 weeks) receiving PCV transfusion were enrolled. USG Doppler study of ACA was done before and after PCV transfusion. Peak systolic velocity (PSV), end-diastolic velocity (EDV) and RI were measured pre and post PCV transfusion.

RESULTS Thirty infants were included in the study, with median gestation age of 28.8 [interquartile range $\{I Q R\}, 27-30.55]$ weeks and median birth weight of 970 [interquartile range $\{I Q R\}, 869.5-1190]$ grams.

There was a significant decrease in PSV pre and post PCV transfusion - $58.46( \pm 18.44) \mathrm{cm} / \mathrm{sec}$ and 46.34 $( \pm 13.93) \mathrm{cm} / \mathrm{sec}$ respectively ( $p$ value $<0.001)$. Changes in RI and EDV were non-significant.

CONCLUSION PCV transfusion significantly decreased PSV, reflecting improved cerebral oxygenation, and decreased cardiac output after correction of anaemia. Laboratory threshold for PCV transfusion in stable preterm infants are not known. USG Doppler study has the potential to provide one of the objective criteria for PCV transfusion in these infants though large scale randomized controlled trials are needed to prove its efficacy.

\section{Background}

An estimated 15 million babies are born preterm every year, globally [1]. The largest number of preterm births occurs in India. [2]. Anaemia is a frequent complication of prematurity and is known to compromise the neurological development of the preterm infants. Many cause lead to anaemia in these babies. Firstly, premature infants do not complete the third trimester of gestation and it is at this stage the maximum iron transport occurs through the placenta. Secondly, at this stage of development, erythropoiesis mainly occurs in the liver and the bone marrow. The liver is less responsive to anemia in stimulating an erythropoietin response. In addition, preterm infants undergo frequent blood tests in neonatal intensive care units (NICU). All these mechanisms of, rapid growth, multiple blood samplings and insufficient erythropoiesis contribute to anemia and its severity. Blood transfusions are common in neonatal units with the intention to maintain optimal tissue oxygenation and promote growth. $[3,4]$.

One of the principal objectives of blood transfusion in preterm infants is to prevent impaired tissue oxygenation of vital organs and brain.[5]. The benefits of blood transfusion in stable preterm infants with respect to neurological outcomes are not clear. 
The main variables affecting cerebral oxygen delivery are cerebral blood flow and haemoglobin concentration [6]. Cerebral blood flow can be measured at the bedside by using non-invasive Doppler ultrasound scan of contributing arteries. The internal carotid artery, basilar artery, anterior cerebral artery and lenticulostriate arteries can be easily visualized with color Doppler imaging [7]. Blood flow can be evaluated by measuring peak systolic velocity (PSV), end-diastolic velocity (EDV) and calculating resistive index (RI). RI measures vascular resistance and is defined as (PSV - EDV) /PSV [8]. A high RI corresponds to vasoconstriction and low blood flow velocity, whereas a low RI is related to vasodilation and high blood flow velocity [9].

Determining peak velocity of systolic blood flow in the middle cerebral artery as an indicator of the severity of anemia is well-documented in fetuses.[10] Researchers have shown that blood transfusions improve cerebral oxygen supply and induce a decrease in cerebral blood flow velocity, by using near infrared spectroscopy (NIRS) and cerebral doppler ultrasonography [11-13]. But there is paucity of robust data on effect of blood transfusions on the cerebral hemodynamic from India. Our study is aimed to document the changes in cerebral blood flow after packed cell transfusion in stable preterm infants.

\section{Methods}

A prospective observational study was done from April 2018 to December 2019, in a tertiary level NICU at Pune, India. All stable preterm infants receiving packed cell transfusions for clinical indications and a haemoglobin value of less than $10 \mathrm{gm} / \mathrm{dl}$ during the study period were enrolled after obtaining written informed consent from parents. Prior ethics approval was taken from the Bharati Vidyapeeth Medical College Institutional ethics committee before starting the study. Preterm infants needing cardiorespiratory support, with major congenital malformations and genetic syndromes were excluded. Transcranial colour Doppler ultrasonography was done 1 hour before packed cell transfusion and 24 hours after post transfusion by neonatologist who was trained in cranial ultrasonography using a SIEMENS machine (Acuson X 300, SIEMENS Medical Solution) with neonatal probe (5-10 Hz transducer). Doppler imaging of the anterior cerebral artery (ACA) was through the anterior fontanelle in the sagittal plane (Fig. 1). Pulse doppler was done to measure PSV and EDV (Fig. 2). RI was then calculated using the formula: RI= (PSV-EDV)/PSV. All measurements were done in thermo-neutral environment ensuring normal body temperature without any pressure provocation in quite infants, using oral sucrose as pacifier with continuous monitoring of oxygen saturation and vitals. Three measurements were recorded each time and mean was calculated. Protocols followed were according to institutional guidelines. Statistical analysis was done using SPSS software version 25.0. Paired t test was used to test the mean difference between RI, PSV and EDV. Throughout the results $5 \%$ level of significance was used. All results are shown with $95 \%$ confidence interval, with p-value of less than 0.05 been considered significant.

\section{Results}


Thirty infants were included in the study, with median gestation age of 28.8 [interquartile range $\{$ IQR\}, 2730.55] weeks, median birth weight of 970 [interquartile range $\{I Q R\}, 869.5-1190]$ grams. Pre-transfusion median haemoglobin was 8.1 [interquartile range $\{I \mathrm{QR}\}, 7.1-8.7] \mathrm{g} / \mathrm{dl}$ (Table 1). Pre and post transfusion mean RI were $0.83( \pm 0.07)$ and $0.82( \pm 0.07)$ respectively ( $p$ value 0.17$)$. Pre and post transfusion PSV were $58.46( \pm 18.44) \mathrm{cm} / \mathrm{sec}$ and $46.34( \pm 13.93) \mathrm{cm} / \mathrm{sec}$ respectively $(p$ value $<0.001)$ and pre and post transfusion EDV were $9.83( \pm 6.64) \mathrm{cm} / \mathrm{sec}$ and $8.47( \pm 5.15) \mathrm{cm} / \mathrm{sec}(p$ value 0.21$)$ (Table 2).

Table 1

Baseline characteristics of the population

\begin{tabular}{|lllll|}
\hline & Minimum & Maximum & Median (IQR) & $\begin{array}{l}\text { Frequency (Percentage) } \\
(\mathbf{n}=\mathbf{3 0})\end{array}$ \\
\hline Birth weight (Grams) & 755 & 1455 & $970(869.5-1190)$ & \\
\hline Gestation age (Weeks) & 26.10 & 34.60 & $28.8(27-30.55)$ & $20(66.7 \%)$ \\
\hline Male & & & & $7 / 23(23.3 \% / 76.7 \%)$ \\
\hline SGA/AGA & & & & $12(40 \%)$ \\
\hline Vaginal delivery & & & & \\
\hline Pre transfusion $\mathrm{Hb}(\mathrm{g} / \mathrm{dl})$ & 6.70 & 10.00 & $8.1(7.1-8.7)$ & \\
\hline
\end{tabular}

Table 2

Pre and post PCV transfusion RI, PSV, EDV

\begin{tabular}{|llll|}
\hline & $\begin{array}{l}\text { Pre PCV } \\
\text { Mean (SD) }\end{array}$ & $\begin{array}{l}\text { Post PCT } \\
\text { Mean (SD) }\end{array}$ & P-value \\
\hline RI & $0.83(0.07)$ & $0.82(0.07)$ & 0.17 \\
\hline PSV (cm/sec) & $58.46(18.44)$ & $46.34(13.93)$ & $<0.001$ \\
\hline EDV (cm/sec) & $9.83(6.64)$ & $8.47(5.15)$ & 0.21 \\
\hline
\end{tabular}

\section{Discussion}

In this study we found a significant decrease in PSV post transfusion but changes in RI and EDV were non-significant. These results are in line with the previously published studies, which showed that blood transfusion decreases the cerebral blood flow velocity [11-13].

Anaemia may lead to increase in cardiac output and cerebral vasodilation, as a compensatory mechanism to increase the oxygenation of brain parenchymal tissue. Previous studies have documented that blood transfusion decrease cardiac output and heart rate. [14]. The decrease cerebral blood flow velocity effect of transfusion can be explained by the reduced cardiac output after the correction of anaemia. Decrease in systolic velocity, may also reflect cerebral vasoconstriction due to improved 
cerebral oxygenation. Cerebral blood flow is also affected by fetal hemoglobin concentration [15]. On transfusing adult hemoglobin, oxygen delivery capacity of blood to the tissues increases, further resulting in decrease of cerebral blood flow.

Caution should be excised as flow should not be equated with blood velocity measured via Doppler study. Cerebral blood flow velocity also depends on the cross-section area of the vessel. Unfortunately, diameter of the cerebral blood vessels cannot be measured accurately by the currently available USG machines, therefore we have to rely on the cerebral blood flow velocity to estimate the cerebral blood flow.

Change in only PSV, with no significant change in RI and EDV, may represent ongoing adaptive mechanism after PCV transfusion. Also, PSV and EDV depends on the angle of insonation, whereas RI being a ratio, is not affected by the angle of insonation. [16]. The difference in PSV, could be due to the intra-observer bias or due to change of angle of insonation, between the pre and post PCV transfusion velocity readings. However, we tried to minimize the bias, by standardizing the area, where Doppler was acquired. Angle of insonation was always less than 15 degrees. All readings were measured by same individual.

In spite of many trials and clinical guidelines the criteria for PCV transfusion in preterm babies are not very clear. Frequently, preterm babies receive packed cell transfusion based on clinical signs of inadequate weight gain, tachycardia, tachypnoea, or persistent oxygen requirement. [17] Liberal transfusion increases the risk of transmission of infection, bronchopulmonary dysplasia, necrotising enterocolitis and retinopathy and simultaneously increases the cost of NICU stay [18-20]. On the other hand, restrictive regime may increase the chances of chronic hypoxemic changes, intraparenchymal brain haemorrhage or periventricular leukomalacia [21]. Some studies showed no difference in neonatal mortality or major morbidity when lower haemoglobin threshold was kept for transfusion, but some showed weak evidence of improved long-term outcome with higher threshold. [22, 23, 24].

Researchers have explored the possibility of using cerebral blood flow velocities to define a threshold for transfusion in preterm babies [14]. This approach seems a distant possibility for lack of data from randomised controlled trials.

\section{Conclusion}

The hemoglobin threshold for the PCV transfusion in stable preterm infants is still elusive, in spite of many trials. This probably reflects the need of defining blood transfusion threshold by considering not only the clinical and laboratory parameters but also haemodynamic parameters. Doppler studies may provide one such vital parameter.

\section{List Of Abbreviations}

PCV - packed cell volume 
$\mathrm{RI}$ - resistive index

ACA - anterior cerebral artery

PSV - Peak systolic velocity

EDV - end-diastolic velocity

IQR - interquartile range

NICU - neonatal intensive care units

NIRS - near infrared spectroscopy

\section{Declarations}

\section{Ethics approval and consent to participate}

Prior ethics approval was taken from the Bharati Vidyapeeth Medical College Institutional ethics committee before starting the study. The study was carried in accordance with the guidelines of Bharati Vidyapeeth Medical College. Informed consent was obtained from parents prior to enrolling infants in the study.

\section{Consent for publication}

Not applicable

\section{Availability of data and materials}

The datasets used and/or analysed during the current study are available from the corresponding author on reasonable request

\section{Competing interests}

The authors declare that they have no competing interests"

\section{Funding}

Not applicable

\section{Authors' contributions}

CC, PS, NNZ: conceived the study; CC, NNZ, BG, RG, AV, PP: did the data collection, analysis and interpretation; CC, NB, SD, PS, NNZ, RG, AV, PP, BG: wrote the first draft which was the read, revised and approved by all the authors. All authors approved the final version of manuscript, and are accountable for all aspects related to the study. 


\section{Acknowledgement}

We would like to acknowledge the technical support provided by Mr. Rupeshkumar Deshmukh, for his contribution in statistics for this research.

\section{References}

1. Liu L, Oza S, Hogan D, Chu Y, Perin J, Zhu J, et al. Global, regional, and national causes of under-5 mortality in 2000-15: an updated systematic analysis with implications for the Sustainable Development Goals. Lancet. 2016;388(10063):3027-35.

2. Blencowe H, Cousens S, Oestergaard M, Chou D, Moller AB, Narwal R, Adler A, Garcia CV, Rohde S, Say L, Lawn JE. National, regional and worldwide estimates of preterm birth. The Lancet, June 2012. 9;379(9832):2162-72. Estimates from 2010.

3. Strauss RG (2010), Anemia of Prematurity: Pathophysiology and treatment. Blood Rev; 24(6): $221-$ 225.

4. Valieva OA, Strandjord TP, Mayock DE, Juul SE. Effects of transfusions in extremely low birth weight infants: a retrospective study. J Pediatr 2009; 155:331-37e1.

5. Paulson OB, Strandgaard S, Edvinsson L. Cerebral autoregulation. Cerebrovascular and brain metabolism reviews 1990; 2:161-92.

6. Ramaekers VT, Casaer P, Marchal G, Smet M, Goosen W. The effect of blood transfusion on cerebral blood flow in preterm infants: a Doppler study. Dev Med Child Neurol 1988; 30: 334-41

7. Couture A, Veyrac C, Transfontaneller Doppler imaging in neonates (2001). Springer, Berlin

8. Lowe LH, Bailey Z (2011) State-of-the-art cranial sonography: part1, modern techniques and image interpretation. AJR Am J Roentgenol 196:1028-1033.

9. Archer LN, Levene MI, Evans DH. Cerebral artery Doppler ultrasonography for prediction of outcome after perinatal asphyxia. Lancet.1986;15:1116-7

10. Mari G, Zimmermann R, Moise KJ Jr, Deter RL. Correlation between middle cerebral artery peak systolic velocity and fetal hemoglobin after 2 previous intrauterine transfusions. Am J Obstet Gynecol 2005; 193 (3 Pt 2): 1117-20

11. Dani C, Pezzati M, Martelli E, et al. Effect of blood transfusions on cerebral haemodynamics in preterm infants. Acta Paediatr 2002; 91: 938-41

12. Liem KD, Hopman JC, Oeseburg B, et al. The effect of blood transfusion and haemodilution on cerebral oxygenation and haemodynamics in newborn infants investigated by near infrared spectrophotometry. Eur J Pediatr 1997; 156: 305-10.

13. Dani C, Pratesi S, Fontanelli G, et al. Blood transfusions increase cerebral, splanchnic, and renal oxygenation in anemic preterm infants. Transfusion 2010; 50: 1220-6.

14. Mirja Quante1 et al. Effects of anaemia on haemodynamic and clinical parameters in apparently stable preterm infants, Blood Transfus 2013; 11: 227-32 DOI 10.2450/2012.0171-11 
15. Lipp-Zwalhen AE, Muller A, Tuchschmid P, Duc G. Oxygen affinity of hemoglobin in modulates cerebral blood flow in premature infants. A study with the non-invasive xenon-133 method. Acta Paediatr Scand 1989; 360: S26-32

16. Seibert JJ, McCowan TC, Chadduck WM et al (1989) Duplex pulsed Doppler US versus intracranial pressure in the neonate: clinical and experimental studies. Radiology 171:155-159

17. Stockman J. Anemia of prematurity and the decision when to transfuse. Adv Pediatr 1983; 30: 191219

18. Crowley M, Kirpalani H. A rational approach to red blood cell transfusion in the neonatal ICU. Curr Opin Pediatr 2010; 22: 151-7.)

19. Valieva OA, Strandjord TP, Mayock DE, Juul SE. Effects of transfusions in extremely low birth weight infants: a retrospective study. J Pediatr 2009; 155: 331-7 e1.

20. Chen HL, Tseng HI, Lu CC, et al. Effect of blood transfusions on the outcome of very low body weight preterm infants under two different transfusion criteria. Pediatr Neonatol 2009; 50: 110-6

21. Bell EF, Strauss RG, Widness JA, et al. Randomized trial of liberal versus restrictive guidelines for red blood cell transfusion in preterm infants. Pediatrics 2005; 115: 1685-91

22. Kirpalani H, Whyte RK, Andersen C, et al. The premature infants in need of transfusion (pint) study: A randomized, controlled trial of a restrictive (LOW) versus liberal (HIGH) transfusion threshold for extremely low birth weight infants. J Pediatr 2006; 149: 301-7 e3

23. Whyte RK, Kirpalani H, Asztalos EV, et al. Neurodevelopmental outcome of extremely low birth weight infants randomly assigned to restrictive or liberal hemoglobin thresholds for blood transfusion. Pediatrics 2009; 123: 207-13

24. Franz AR, Engel C, Bassler D, Rüdiger M, Thome UH, Maier RF, Krägeloh-Mann I, Kron M, Essers J, Bührer C, Rellensmann G. Effects of Liberal vs Restrictive Transfusion Thresholds on Survival and Neurocognitive Outcomes in Extremely Low-Birth-Weight Infants: The ETTNO Randomized Clinical Trial. JAMA. 2020 Aug 11;324(6):560 - 70.

\section{Figures}




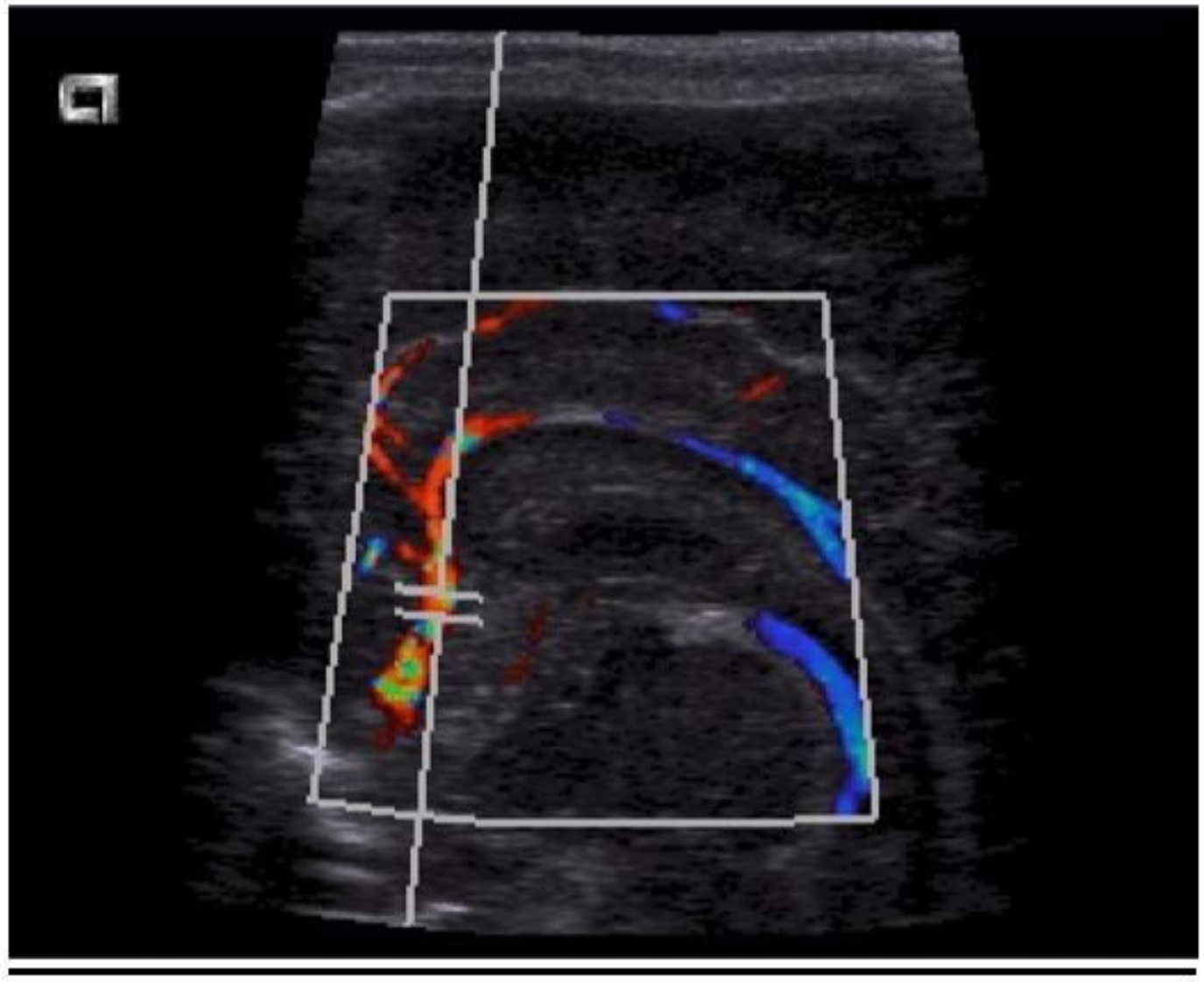

Figure 1

Identification of ACA (Doppler - Angle of insonation $<15^{\circ}$ ) 


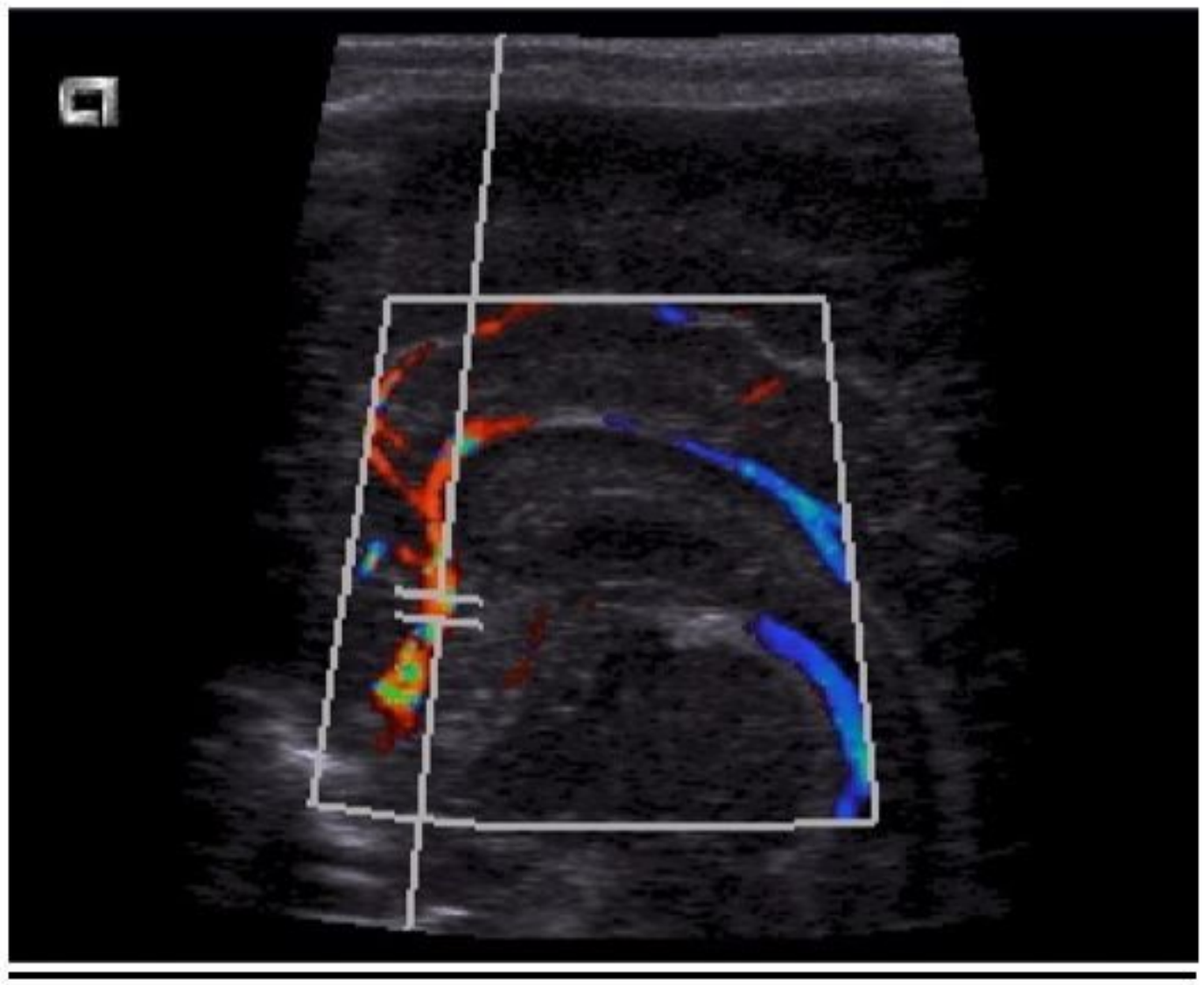

Figure 1

Identification of ACA (Doppler - Angle of insonation $<15^{\circ}$ ) 


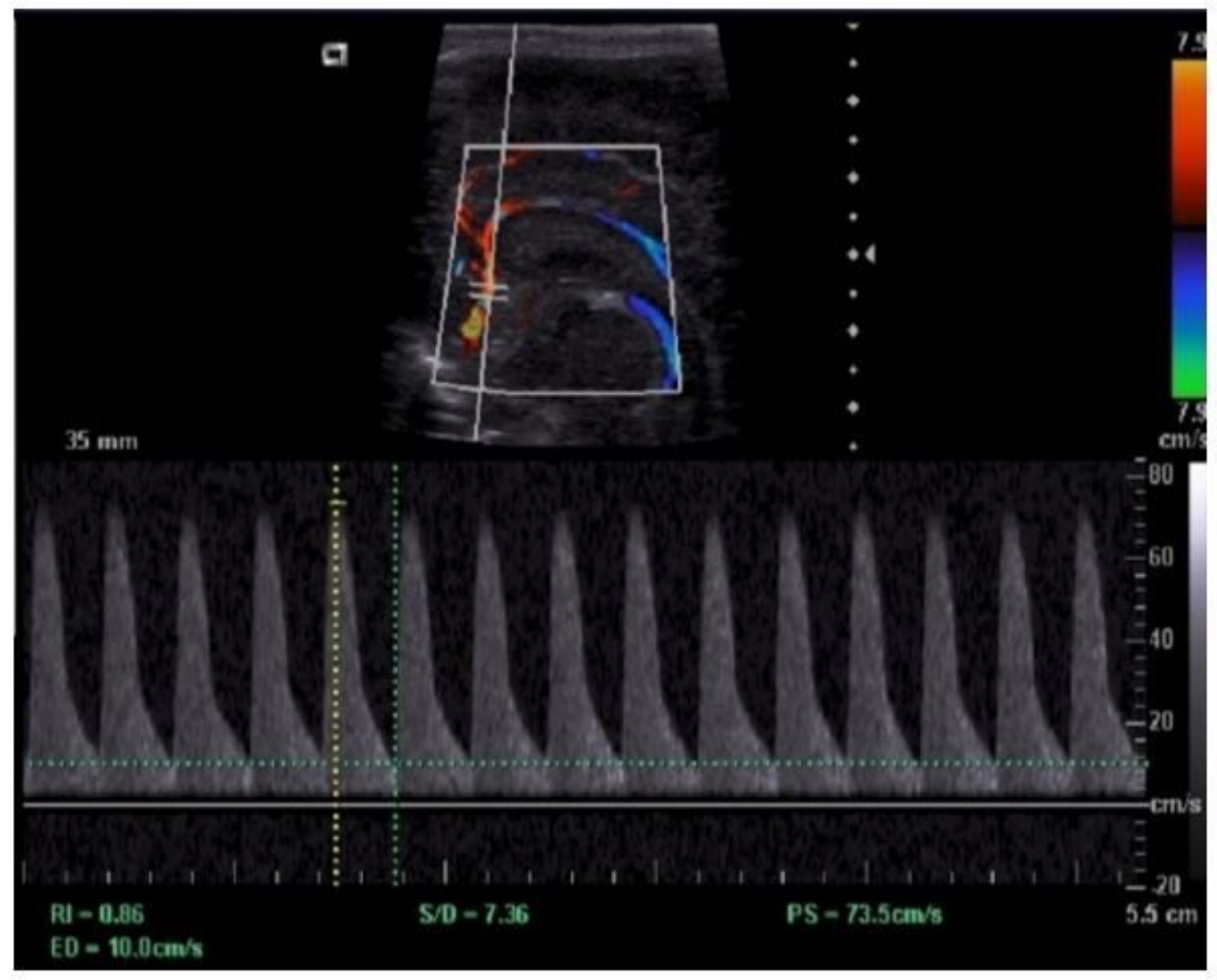

Figure 2

Calculation of PSV, EDV and RI using Doppler in ACA 


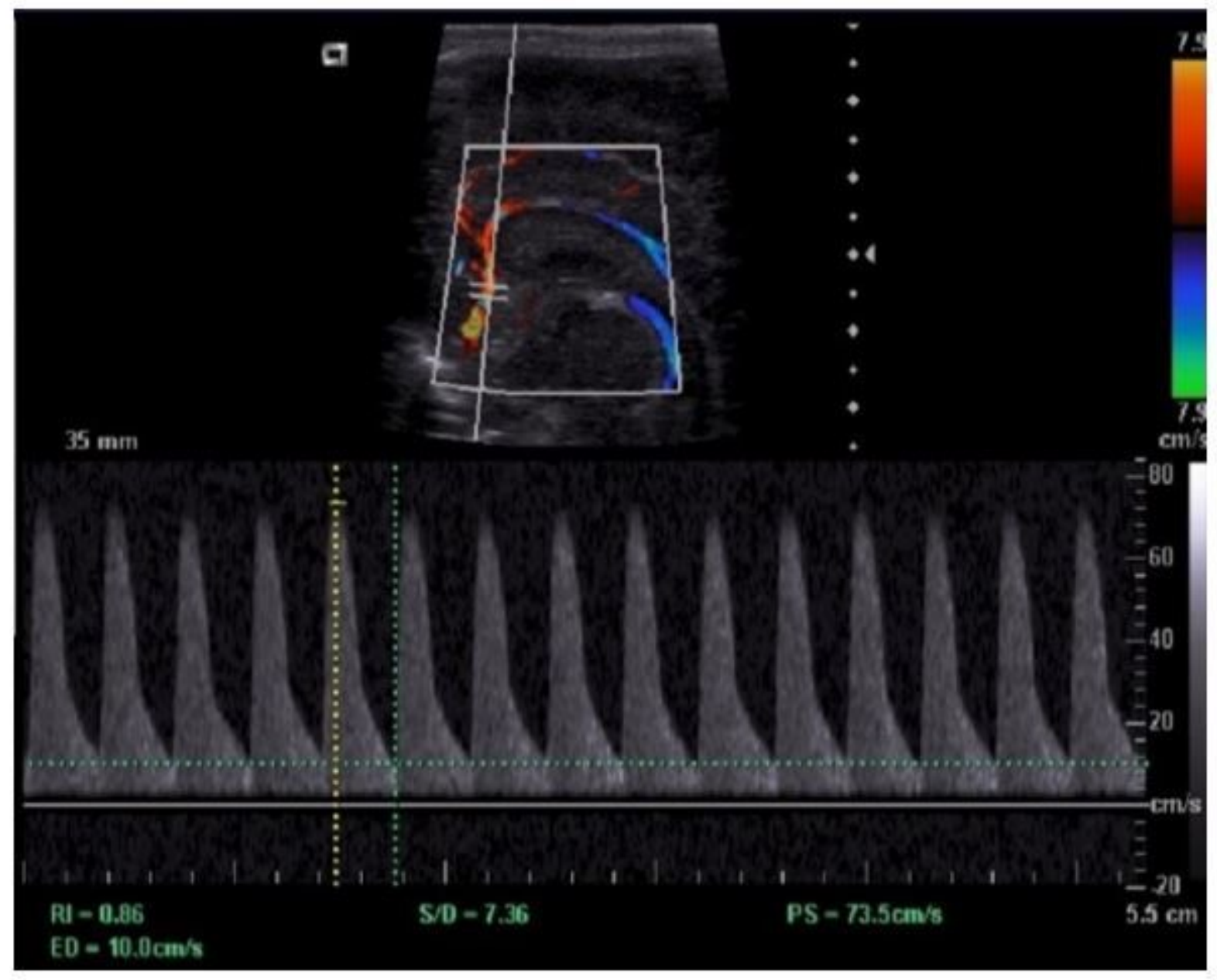

Figure 2

Calculation of PSV, EDV and RI using Doppler in ACA 